\title{
THE OUTBREAK OF AVIAN CHLAMYDIOSIS IN PET SHOP IN THE CITY OF PRAGUE
}

There is a lack of data on incidence of human chlamydiosis (psittacosis) in the Czech Republic as well as in the rest of world. For example, only 91 human cases of psittacosis in the USA (CDC, 2009) and 8 cases in the Czech Republic (EPIDAT, 2009) were reported to their national surveillance authorities in the period 2002-2007. Low medical attention to the role of Chlamydophila psittaci in various health problems could explain non-representative numbers of confirmed psittacosis mentioned. On the other hand the results of veterinary investigation confirm frequent incidence of this pathogen in animals as a main source of infections for humans.

We have confirmed the outbreak of avian chlamydiosis in Prague which included totally 24 birds of various species of Psittaciformes (amazon, parrots, lories, cockatoos, parakeets). We have detected DNA specific for Ch. psittaci in the samples from bird faeces from the pet shop department in Hypermarket HORNBACH in Prague.

First case, Blue Fronted Amazon (Amazona Aestiva) was found with clinical symptoms, such as: lethargy, anorexia, mucopurulent ocular and nasal discharge, and diarrhoea. Other birds in this pet shop were determined as negative. Second group of samples from this breed was tested after treatment of positive Amazon by doxycycline. Ch. psittaci was detected in another 8 various Psittaciformes. Another 5 positive birds were determined in course of the following month. Positive animals were without clinical symptoms. These birds had been treated by using doxycycline for 6 weeks and then confirmed as negative for $C h$. psittaci.

Approximately 100 samples with 12 per cent ratio of positives are being examined for avian chlamydiosis in the Czech Republic every year. We considered nested PCR as the most effective method for Chlamydiacae determination and typing. We found methods based on immune-fluorescence or immune-chromatography not so effective mostly because of their dependence on fresh clinical (section) material and also cross immunological reactivity between various species of the Chlamydiacae.

Outbreaks of chlamydiosis in pet birds represent high risk of zoonotic transmission of Ch. psittaci via near contact between humans and animals in pet shops.

According to the hypothesis based on 10-year- study published by Bazala and Renda in 2005 in the Czech Republic the majority of latent health problems of people having frequent contact with animals (agriculture animals, pet animals etc.) is primary caused by Chlamydiacae. Therefore we believe the investigation of chlamydial outbreaks in animals may improve medical attention to chlamydiosis (psittacosis) in human patients with atypical health disorders with unknown cause.

I. Holko, Faculty of Technology, Tomas Bata University in Zlin T. Holková, State Veterinary Institute in Prague 